\title{
Catalunya i València durant la Guerra de Successió. «La comuna empresa de la llibertat»*
}

\author{
Carme Pérez Aparicio \\ Universitat de València. Departament d'Història Moderna \\ carmen.perez@uv.es
}

Rebut: octubre de 2012

Acceptat: novembre de 2012

\begin{abstract}
Resum
La mort sense descendència de Carles II situava Europa i la Monarquia Hispànica en una autèntica cruïlla. Els dos candidats finals al tron, l'arxiduc Carles d'Àustria i el duc d'Anjou, Felip de Borbó, representaven trajectòries politicodinàstiques ben diferents. Per als Regnes de la Corona d'Aragó, estava en joc la pervivència del sistema pactista i la defensa dels seus projectes i interessos econòmics. En aquest context, Catalunya i València mantingueren una relació ben estreta, d'ajuda mútua, durant l'etapa de govern austriacista, que continuà després de la victòria borbònica d'Almansa i de l'abolició dels Furs de València, en un intent de frenar l'ofensiva militar sobre Catalunya i de restaurar el sistema pactista al Regne de València. Malgrat tot, l'ocupació borbònica de Barcelona i els tractats d'Utrecht i de Rastatt posaren fi a aquests projectes.
\end{abstract}

Paraules clau: Guerra de Successió; Catalunya; València; pactisme.

Resumen. Cataluña y Valencia durante la Guerra de Sucesión. «La comuna empresa de la llibertat»

La muerte sin descendencia de Carlos II situaba a Europa y a la Monarquía Hispánica en una auténtica encrucijada. Los dos candidatos finales al trono, el archiduque Carlos de Austria y el duque de Anjou, Felipe de Borbón, representaban trayectorias político-dinásticas bien diferentes. Para los Reinos de la Corona de Aragón, estaba en juego la pervivencia del sistema pactista y la defensa de sus proyectos e intereses económicos. En este contexto, Cataluña y Valencia mantuvieron una relación muy estrecha, de ayuda mutua, durante la etapa de gobierno austriacista, que continuó después de la victoria borbónica de Almansa y de la abolición de los Fueros de Valencia, en un intento de frenar la ofensiva militar sobre Cataluña y de restaurar el sistema pactista en el Reino de Valencia. A pesar de todo, la ocupación borbónica de Barcelona y los tratados de Utrecht y de Rastatt pusieron fin a estos proyectos.

Palabras clave: Guerra de Sucesión; Cataluña; Valencia; pactismo.

* Aquest treball forma part del Projecte d'Investigació «Cambios y resistencias sociales en los territorios hispánicos del Mediterráneo Occidental en la Edad Moderna», financiat pel Ministerio de Ciencia e Innovación, Projecte n HAR2011-27898-C02.01. 
Abstract. Catalonia and Valencia during the War of the Spanish Succession. "La comuna empresa de la llibertat»

After the childless death of Charles II, Europe and the Spanish Monarchy were placed in a real crossroad. The two final throne's candidates, Charles, archduke of Austria, and Philip of Bourbon, duke of Anjou, represented really different political-dynastic courses. To the Crown of Aragon's Kingdoms, the survival of the constitutional system and their economic interests and projects' defence were at stake. In this context, during the Hapsburg's government, Catalonia and Valencia maintained a close relationship of mutual aid that continued after the Almansa's Bourbon victory and the abolition of Valencia's Statute-Laws, in an attempt to slow down the military offensive over Catalonia and to restore the constitutional system in the Kingdom of Valencia. In spite of everything, Barcelona's Bourbon occupation and the Treaties of Utrecht and Rastatt ended these projects.

Keywords: War of the Spanish Succession; Catalonia; Valencia; Parliamentarian system.

\section{Sumari}

1. Què hi havia en joc, amb el canvi dinàstic?

2. A l'espera de la iniciativa internacional
4. La victòria borbònica d'Almansa i la lluita per la supervivència

Bibliografia

3. Els projectes compartits. La rebel-lió dels Regnes de la Corona d'Aragó

L'11 de setembre de 1714 es representà, a Barcelona, l'acte final d'un drama nacional, el del poble català lluitant fins a l'últim alè per defensar la seva identitat i les seves llibertats constitucionals, per la pervivència d'un sistema polític que ja havia estat sentenciat a mort per Felip $\mathrm{V}$ tan prompte es produïren les rebel-lions a la Corona d'Aragó i executat a mesura que les seves tropes van anar recuperant els distints territoris. L'actitud aferrissada dels austriacistes catalans de resistir el setge borbònic va ser compartida i també protagonitzada pels valencians i pels aragonesos que havien cercat refugi a Barcelona després de la victòria filipista d'Almansa. En efecte, pel que respecta als valencians, la desfeta d'Almansa, del 25 d'abril de 1707, representa l'inici d'una ofensiva institucional i d'una resposta social per tal d'evitar allò que en aquell moment semblava ja inevitable, com era l'abolició dels Furs i, amb aquesta acció, la pèrdua de la sobirania, una lluita que, en les diferents manifestacions que va presentar, va estar estretament vinculada a l'austriacisme català, amb el qual va compartir, l'11 de setembre de 1714, un mateix destí. Amb aquesta desfeta i els acords signats a Utrecht i Rastatt, es consolidava el canvi dinàstic, amb les conseqüències polítiques, econòmiques $\mathrm{i}$ socials que comportava. 


\section{Què hi havia en joc, amb el canvi dinàstic?}

El fet de compartir els mateixos interessos no era circumstancial. Com és sabut, la Corona d'Aragó s'havia anat conformant com una Monarquia composta sota un sistema pactista, que constituïa el seu senyal d'identitat en produir-se la unió amb la Corona de Castella, formada per un conjunt de territoris units de manera accessòria sota l'hegemonia castellana. Aquesta identitat històrica diferenciada, plasmada en els sistemes de govern respectius, no havia impedit que els Habsburg tractaren d'avançar per la senda de l'autoritarisme en els Regnes de la Corona d'Aragó, la qual cosa provocava el descontentament en aquests territoris i generava un clima cada vegada més tens en les relacions entre el rei i els Regnes. En conseqüència, no era d'estranyar que la incògnita de la successió suscitara la preocupació pel futur d'aquestes relacions i, fins i tot, que les consideracions a favor o en contra dels candidats no foren coincidents en totes dues Corones. Doncs bé, la mort sense descendents del darrer Àustria, Carles II, en 1700, situava la Monarquia Hispànica, en general, i la Corona d'Aragó, en particular, en una autèntica cruïlla. Però també a Europa. Per damunt de les implicacions internes — de tot tipus - del canvi dinàstic estava en joc l'equilibri internacional, que es podia veure alterat significativament si l'herència hispànica contribuïa a crear un poder hegemònic a Europa. Els tractats de partició acordats per les potències europees principals no feren sinó provocar la protesta i el rebuig del propi Carles II, disposat a garantir la integritat patrimonial mitjançant la designació d'hereu, tal com va fer, el 1698, en la persona del príncep electoral Josep Ferran de Baviera, una candidatura que no sols responia a factors de legitimitat dinàstica, sinó que també garantia el manteniment de l'equilibri internacional. Això no obstant, la mort prematura del príncep, un any després, va deixar en escena les dos candidatures finals al tron espanyol, la de Felip de Borbó i la de l'arxiduc Carles d'Habsburg. Un i altre s'atribuiien un dret preferent, però no van ser raons de legitimitat dinàstica les que mogueren Carles II a designar nou hereu el representant de la Casa de Borbó, sinó que la raó d'Estat (Molas, 2000) li va fer anteposar la necessitat de garantir la integritat territorial de la Monarquia i d'evitar una nova guerra amb Lluís XIV — que amenaçava de reclamar l'herència hispana per la força. Aquesta consideració va passar davant dels drets de la Casa d'Àustria, l'ajut militar de la qual esdevindria inoperant per la distància. I ho va fer «no sin repugnancias de la voluntad, vencida de la razón», en paraules del marquès de San Felipe ${ }^{1}$.

La decisió del darrer Habsburg responia al parer majoritari de la classe política cortesana, però no mancaren veus favorables als austríacs, com la del comte de Frigiliana, membre del Consell d'Estat i governador de la presidència del Consell d'Aragó, molt conscient de les conseqüències negatives que podien desencadenar-se en el cas que un Borbó assolira el tron. Segons la seva opinió, era un greu

1. V. Bacallar i Sanna, marquès de San Felipe (s. a. 1725), Comentarios de la Guerra de España e Historia de su Rey Phelipe V el Animoso, 2a ed., Gènova, estudi preliminar i notes de C. Seco Serrano, Madrid, 1957, p. 15. 
error lliurar la Monarquia a França i convertir el Cristianíssim en àrbitre d'Europa, ja que això provocaria la resposta immediata de l'emperador, així com el rebuig de les potències marítimes, contraposades a França per interessos econòmics, polítics i religiosos, i també d'altres prínceps europeus que havien sostingut tantes guerres per a mantenir l'equilibri internacional. A més, hi havia el perill que es declarés una guerra civil, i tot plegat podia portar al desmembrament de la Monarquia. Malgrat això, no trobava fàcil elegir el camí que calia seguir, perquè considerava molt incert el futur dels Regnes hispànics, fins i tot en el cas que, units a la Casa de Borbó, els francesos resultaren victoriosos. El temor a un canvi del sistema de govern planava, segons ell, sobre el futur de la Monarquia:

Y no sé si sea más deseable que, estando nosotros unidos con los franceses, quedásemos victoriosos o vencidos, si consideramos con madurez que siempre tendremos más que temer de los franceses victoriosos que de los mismos enemigos. Aquellos, ahora más complacientes y por eso aplaudidos, pero soberbios e imperiosos, nos mirarán después con desprecio y tratarán como un pueblo de conquista; aquellos, al contrario, deseando solo el equilibrio de las potencias en Europa, no alterarán ciertamente nuestras leyes, no pretenderán nuestras dignidades, no destruirán nuestros privilegios y no causarán el menor menoscabo a nuestras prerrogativas. Decidme ahora, y consideradlo vosotros mismos que me escucháis, si puede sobrevenir mayor desgracia que la de no saber lo que más debemos desear o temer ${ }^{2}$.

Com no podia ser d'altra manera, les implicacions internacionals de la manca de successió interferien directament en l'escenari polític espanyol, marcat per una trajectòria d'enfrontaments entre el rei i els Regnes no castellans, com va quedar de manifest en la crisi de 1640. En aquells moments, el fracàs del projecte olivarista va tindre un preu, la independència de Portugal, que comportà la ruptura de la unitat peninsular, però el retorn de Catalunya al si de la Monarquia no va evitar que, a partir de 1652, si bé va mantenir el sistema de govern establert en les Constitucions, haguera de suportar la presència d'un contingent militar al Principat i la ingerència del rei en el procés d'insaculació per als oficis de la Generalitat i la Ciutat de Barcelona. Durant la segona meitat del segle XVII, les reivindicacions per recuperar l'statu quo ante foren una constant en les difícils relacions entre el rei i Catalunya, així com la defensa del sistema constitucional (Simon, 2011). Aquestes i les denúncies de contrafaccions a Catalunya o de contrafurs al Regne de València, en definitiva, les tensions polítiques, marcaren el desencontre dels Regnes de la Corona d'Aragó amb la Monarquia.

Amb aquests antecedents, la primera valoració que calia fer, llavors, de les diferents candidatures al tron espanyol havia de ser necessàriament política, tant per part de la Corona de Castella com de la Corona d'Aragó, representants, l'una i l'altra, de trajectòries i models polítics ben diferents. A l'Europa occidental,

2. F. DE CAStellví (1997-2002), Narraciones históricas, manuscrit existent en l’Österreichisches Staatsarchiv, de Viena, edició de J. M. Mundet i Gifré i J. M. Alsina Roca i estudi preliminar de F. Canals Vidal, 4 vols., Madrid, vol. I, p. 171-172. Existix una còpia del manuscrit a 1'Arxiu Nacional de Catalunya amb el títol Narraciones históricas desde el año 1700 al 1725. 
la dinastia francesa era l'exponent més clar d'una política absolutista, centralista i militarista, que encaixava de ple en el sistema de govern i en els projectes de futur d'amplis sectors de la Corona de Castella, però generava greus recels a la Corona d'Aragó, fermament decidida a mantenir el seu sistema constitucional i l'organització confederal dels territoris que la integraven. Per aquesta raó, la Casa d'Àustria constituïa la millor opció, malgrat els avenços de l'autoritarisme monàrquic aconseguits al llarg de dues centúries. És cert que, en un territori i l'altre, l'arribada al tron de Madrid de la dinastia gal-la aportava un avantatge indiscutible, com era el d'establir unes bases sòlides per tal d'acabar amb la secular enemistat francoespanyola, que tantes pèrdues humanes i econòmiques havia provocat. Això contribuiia a enfortir, sens dubte, l'opció de la Casa de Borbó a la Corona de Castella, però en res no debilitava la candidatura dels Àustria a la Corona d'Aragó, a favor de la qual comptaven, a més a més, unes altres consideracions igualment negatives cap a Felip de Borbó, com ara el temor d'una competència més dura dels productes francesos i el ferm desig de mantenir i estrènyer els lligams comercials existents amb les potències marítimes, Anglaterra i les Províncies Unides, que, en 1701, amb la signatura de la Gran Aliança de l'Haia, donaren suport a la candidatura austríaca. Més endavant, iniciat ja el conflicte successori, s'afegiren a favor del candidat austríac les promeses fetes pels seus emissaris, que consistien a atendre les reivindicacions antisenyorials existents en el camp valencià, però que tampoc no faltaven a la resta dels territoris.

D'altra banda, el recel que despertava la dinastia francesa a la Corona d'Aragó està present en molts testimonis de l'època, de manera directa o indirecta, començant pel propi testament de Carles II, en el qual ell —que no havia jurat les Constitucions de Catalunya ni els Furs de València, ni com a príncep hereu ni com a rei- recollia l'obligació dels súbdits de donar possessió al nou rei «precediendo el juramento que deve hacer de observar las Leyes, Fueros y Costumbres de dichos mis Reynos y Señoríos» ${ }^{3}$. També la Junta de Govern tractà de neutralitzar el malestar creat per les disposicions d'un suposat Reial Despaig d'1 de novembre, que el rei no havia pogut signar perquè li havia sobrevingut la mort, entre les quals hi havia la del manteniment de la Planta de Govern, que es justificava «por ser la que más conviene a vuestra más segura defensa y conservación de los Fueros, Privilegios Usos y Costumbres de esse Reyno» ${ }^{4}$. A més de la còpia de les clàusules testamentàries i del Reial Decret, els Estaments valencians, com a representants del Regne, van rebre una lletra del comte de Frigiliana, governador de la presidència del Consell d'Aragó i conseller d'Estat, on es feia una crida a l'obediència de les disposicions reials, la finalitat de les quals era «procurar el logro de quedar en los términos de observancia de los Fueros, Privilegios y Prerrogativas de cada Provincia»5. El mateix expressava el propi Lluís $\mathrm{XIV}$, en recomanar al seu nét que visités aquests territoris i jurés les seves lleis,

3. Testamento de Carlos II, edició facsímil, transcripció i estudi preliminar d'Antonio Domínguez Ortiz, Madrid, 1982, p. 43-49.

4. Arxiu del Regne de València (ARV), Real, 558, f. 146r.-147v.

5. Ídem. 
per fer veure a aquests pobles, zelosos dels seus privilegis, que no tenia intenció de suprimir-los ${ }^{6}$. També l'historiador borbònic valencià Josep Manuel Minyana, a l'inici de la seua obra De bello rustico valentino, contraposava el que ell qualificava d' «imperio plácido y benigno» de la casa d'Àustria a la francofobia generada per les guerres i la dura competència comercial ${ }^{7}$, un rebuig cap als francesos i la Casa de Borbó que havia penetrat en tota la població i que, en el cas valencià, era recollit pel mateix virrei, el marquès de Villagarcia, qui es va fer ressò ben aviat del clima favorable a la Casa d'Àustria i «el recelo de que, entrando la de Borbón, experimentarían el severo y riguroso gobierno que publican del Rey Christianísimo» ${ }^{8}$. En tot cas, Felip V no estigué a l'alçada de les seues obligacions i, en el cas valencià, el fet de no haver jurat els Furs ni convocar Corts contribuí, sens dubte, a mantenir els recels cap a la nova dinastia.

\section{A l'espera de la iniciativa internacional}

Malgrat tot, el fet que els Regnes hispànics de la Corona d'Aragó compartiren, en termes generals, un mateix projecte polític, interessos econòmics i reivindicacions socials semblants, això no va donar pas a una resposta immediata, unànime ni contundent de rebuig al testament de Carles II, que designava hereu el duc d'Anjou. Mentre el Regne d'Aragó, com a cap de la Corona, era partidari de convocar una Junta General, com la que es va reunir a Casp, per a tractar de la successió, i mentre Catalunya expressava les seves discrepàncies sobre les suposades disposicions del darrer Âustria, el Regne de València, des d'una postura rotundament pragmàtica, es va manifestar partidari, sense cap objecció explícita ni aparent, d'acatar el testament i les disposicions del rei difunt, reconeixent que la voluntat reial havia estat la de «mirar per la pau, quietud y unió de sos afligits vasalls, observància de sos Privilegis, Furs, Usos y bons Costums y universal conservació de esta Cathòlica Monarquia» ${ }^{9}$. No obstant aquests titubejos inicials, Aragó, Catalunya i Mallorca no trigaren gaire a sumar-se a la decisió adoptada pel Regne de València, perquè ni els Regnes disposaven de recursos econòmics o militars per a fer efectiu el seu hipotètic desacord, ni era viable dur fins a les últimes conseqüències un enfrontament contra els Borbons de totes dues bandes dels Pirineus ${ }^{10}$. Per contra,

6. A. Baudrillart (I890), Philippe V et la Cour de France, 5 vols., París, vol. I, p. 92. Existix una traducció al castellà del volum I, amb el títol Felipe V y la corte de Francia, tom I, Felipe V y Luis XIV, edició i coordinació de C. Cremades, Murcia, 2001, volum I, p. 106.

7. J. M. Miñana (I752), De bello rustico valentino, l'Haia. La primera traducció al castellà fou publicada per V. Castañeda en Revue Hispanique, LV, 1922, p. 447-618 (la citació és a la pàgina 456). Hi ha una nova edició revisada del text llatí i una nova traducció amb el títol La Guerra de Sucesión en Valencia, edició a càrrec de F. J. Pérez Durà i J. Mª . Estellés i González, València, 1985, p. 33.

8. Archivo Histórico Nacional (AHN), Estado, 1lib. 216, lletra del virrei al president del Consell d'Aragó de 15 de març de 1701.

9. ARV, Real, 558, f. 162v.-164r.

10. Cal no oblidar que el governador de Castelló, don Andreu Montserrat, informava el virrei, mitjançant una carta d'11 d'octubre, que Lluís XIV havia desplaçat a la frontera catalana un contingent militar de 26.000 soldats. ARV, Cartas a los virreyes, Felipe V, 213/3. 
era preferible mantenir la prudència i esperar la resposta i les iniciatives que pogueren arribar d'altres països europeus, i especialment de l'emperador.

No obstant això, el que queda clar en aquests primers moments és que els Regnes de la Corona d'Aragó mantingueren una fluida correspondència entre ells per tal de posar en comú una mateixa veu i d'escenificar una mateixa actitud en la Cort ${ }^{11}$, mentre que la Junta de Govern de la Monarquia i els virreis respectius es mostraven molt atents a qualsevol indici de dissidència en aquests territoris. En el cas valencià, el marquès de Villagarcía es manifestava especialment preocupat pels esdeveniments que es pogueren produir a Catalunya, sabedor de l' «eco que puede hazer cualquier novedad del Principado en este Reyno» i encomanava al governador de Sant Mateu enviar algun confident a Tortosa per a «inquirir [...] si vienen noticias melancólicas de Barcelona y, en caso que esto suceda (que Dios no permita), me despache vuestra merced un correo muy ligero que llegue a esta ciudad un día antes de la estafeta» ${ }^{12}$.

Però, malgrat que aquest recel no es va fer patent de forma institucional, les primeres disposicions del virrei revelen fins a quin punt els valencians, en general, i les institucions, en particular, es mostraven atents a qualsevol esdeveniment que poguera produir-se en el Principat. Les raons eren òbvies. En primer lloc, perquè formaven part d'una mateixa Corona, però també pel fet que, al llarg del segle XVII, Catalunya havia estat escenari de grans esdeveniments, la repercussió dels quals havia afectat de ple el Regne de València. En primer lloc, la revolta de 1640, que havia obligat les institucions valencianes a posar en marxa una sèrie de mesures per tal evitar-ne la propagació. Desprès, l'ofensiva militarista duta a terme per Lluís XIV al llarg del regnat de Carles II (Albareda, 1993: 20-31. Torras, 1999: 28-42), raó per la qual el darrer Àustria havia sol-licitat, diverses vegades, la col-laboració dels valencians i els aragonesos en la defensa del Principat (Espino López, 2007). En aquelles circumstàncies, el Regne de València no havia dubtat a prestar ajut en forma de soldats. Ho va fer perquè «de la defensa de aquell Principat redunda la pròpia y peculiar del present Regne» (García Martínez, 1991: 605), una defensa, la pròpia i la general de la Corona, a la qual, cal no oblidar-ho, estaven obligats tots els Regnes i que es convertí en l'argument més rotund per tal d'aconseguir la contribució de totes les poblacions valencianes:

[...] a més de estar tots obligats a sa pròpia defensa, per ser aquella natural; considerada la precissa obligació, que a tots en general corre, de acudir a procurar que no tinguen efecte los danys que poden succehir.

Tot això per solidaritat amb un territori de la pròpia Corona d'Aragó, però també perquè «seria cruel y despiadada resolució contra nosatros mateixos, el no procurar fer lo machor y més adelantat esforç» (García Martínez, 1991: 622-623)

11. Les deliberacions de l'Estament Militar en ARV, Real, 558, f. 200v.-211r. També la Ciutat de València acusà rebut de la comunicació dels diputats de la Generalitat catalana. Arxiu Municipal de València (AMV), Lletres missives, g3 63, f. 143v.-144v.

12. ARV, Cartas a los virreyes, Felipe V, 45/20. 
en la defensa de Catalunya, com va confirmar el bombardeig francès de la ciutat d'Alacant l'any 1691. Estava molt clar que, en aquells moments, la defensa del Principat constituiia la salvaguarda del País Valencià, una situació que es tornarà a repetir a propòsit del conflicte successori.

En aquest marc i amb aquests antecedents, la possibilitat de donar una altra resposta per part de la Corona d'Aragó a l'arribada al tron de Felip V es va posposar fins que, per iniciativa de l'emperador Leopold I, es va formar la Gran Aliança de l'Haia. Un dels primers objectius d'aquesta coalició fou el d'integrar i coordinar tots els grups dissidents, tant de la Corona de Castella com de la Corona d'Aragó o dels altres territoris de la Monarquia, si bé el fet que aquests preparatius es desenvoluparen en la clandestinitat dificulta un coneixement precís del seu complex entramat més enllà de notícies fragmentades sobre intercanvis epistolars, la presència d'emissaris imperials o la circulació de propaganda.

Iniciada ja la guerra i trencades les relacions comercials amb els signants del Tractat de l'Haia, especialment amb Anglaterra i les Províncies Unides, les conseqüències econòmiques hagueren d'influir necessàriament a l'hora de decantar o d'enfortir voluntats a favor de l'arxiduc, però també la política duta a terme per Felip V, de permetre la ingerència del rei de França en els assumptes interns de la Monarquia, d'acceptar disposicions emanades de la Cort de París i —el que era pitjor- en contra dels interessos dels seus súbdits. Malgrat que la comissió de contrafurs en els Regnes de la Corona d'Aragó havia estat una pràctica habitual per part dels Àustria, els comesos durant el regnat del primer Borbó, així com les agressions practicades en els ports pels corsaris i els vaixells de guerra francesos contra les embarcacions de països neutrals i contra els interessos dels comerciants, a qui se'ls obligava a anar a França a reclamar les seues pertinences, causaren, almenys en el port d'Alacant, un autèntic terratrèmol. A més dels afectats, totes les institucions valencianes, la Ciutat i la Batlia d'Alacant, els tres Estaments del Regne i fins i tot el virrei i la Reial Audiència mostraren el seu complet desacord amb les actuacions dels súbdits francesos. També el Consell d'Aragó es veié forçat a plantejar a Felip V l'obligació, i fins i tot la conveniència, en aquelles difícils circumstàncies, de respectar els Furs i d'actuar amb tota la contundència possible en defensa de la seva sobirania, dels interessos dels seus súbdits $\mathrm{i}$ de la salvaguarda de les embarcacions ancorades en els ports sota l'estendard reial (Pérez Aparicio, 2008: I, 315-345). D’altra banda, és difícil trobar disposicions relatives al comerç que no resultaren altament lesives per als interessos dels diferents sectors econòmics valencians i favorables als francesos, la qual cosa comportà un agreujament de la francofòbia que caracteritzava també la societat valenciana.

\section{Els projectes compartits. La rebel·lió dels Regnes de la Corona d'Aragó}

La Corona d'Aragó va entrar en l'escenari internacional del conflicte l'any 1703, a causa de la primera incursió aliada en les seves costes, fins a culminar, en agost de 1705, amb el desembarcament a Dénia de don Joan Baptista Basset i Ramos i la proclamació de Carles III. Des del primer moment, quedà ben clar que l'objec- 
tiu prioritari era Catalunya. En un manifest datat el 15 d'agost al navili Gran Bretanya, l'arxiduc es dirigia als valencians per a donar-los a conèixer la seva presència, rumb al Principat, on s'executarien les operacions necessàries per tal d'alliberar la Monarquia del jou imposat per Felip de Borbó i per a anunciar el seu compromís «de acudir al amparo y defensa de este Reyno luego que las disposiciones más precisas de nuestro servicio sean executadas en Cathaluña» ${ }^{13}$. Així, s'obrí un compàs d'espera al País Valencià en funció dels esdeveniments que pogueren produir-se al nord del riu de la Sènia.

Dénia fou la primera població de la Corona d'Aragó i de la Monarquia que es va rebel-lar contra Felip V el 18 d'agost de 1705. El govern borbònic va enviar tropes immediatament, però l'intent de recuperar-la va fracassar quan Felip V decidí concentrar els seus recursos al Principat, convertit, pel desembarcament aliat, en l'objectiu prioritari dels dos contendents. Totes les tropes borbòniques enviades a Dénia foren contramanades a Catalunya, totes a excepció d'un regiment de catalans, la fidelitat del qual era motiu de recel i desaconsellava el retorn a la seva terra. A partir d'aquests fets, els esdeveniments catalans tingueren un impacte directe sobre el País Valencià. Les institucions valencianes no sols es mostraven preocupades pel focus austriacista de Dénia i el fort suport que li prestaven els pobles de la Marina, sinó també per les notícies que arribaven de Catalunya sobre el setge aliat al qual estava sotmesa Barcelona i sobre el triomf de la rebel-lió en diferents comarques. Els preocupava de manera especial la situació de Tortosa, considerada l'antemural del Regne, per la seva situació estratègica, la qual cosa li permetia dominar una àmplia extensió de territori a una banda i l'altra de l'Ebre. De fet, la caiguda de Tortosa, a les darreries del mes de setembre, produí un efecte de contagi immediat a les terres del nord del País Valencià, «la mayor parte se a olgado, prometiéndose llegarà el día de juntarse con ellos», i especialment a Vinaròs, que es va rebel-lar el dia 7 d'octubre gràcies a l'ajut prestat pels miquelets catalans ${ }^{14}$.

Aquests dos focus austriacistes valencians, incomunicats per terra per sengles regiments borbònics, desenvoluparen, no obstant això, una intensa activitat per mar, en estreta relació amb Catalunya i amb la resta del País, a l'espera dels esdeveniments finals al Principat. Sense més recursos militars que dos regiments, destinats només a bloquejar Dénia i Vinaròs, la resta del territori es trobava totalment desprotegida, mentre l'activisme dels seguidors de l'arxiduc augmentava i generava un clima d'inseguretat que les institucions valencianes transformaren en tota una allau de peticions de socors. No obstant això, el Govern borbònic, mancat de mitjans suficients per defensar Catalunya, no pogué atendre les necessitats militars del Regne i el deixà abandonat a la seua sort. Aquesta indefensió va ser denunciada una vegada i una altra pels tres Comuns, Ciutat, Regne i Diputació, com també per uns altres personatges de gran rellevància, com ara l'arquebisbe de València, qui va plantejar al rei la impossibilitat que un sol regiment —el que

13. AHN, Estado, lligall 265/33.

14. Ibídem. Lletra de don Joan Antoni Hurtado de Amézaga a don Joseph Grimaldo de 30 de setembre de 1705 . 
bloquejava Vinaròs - servira per a «detener la corriente de sedición de Cataluña y asegurar que no levanten otra semejante nuestros paisanos»15. Les raons eren contundents, especialment després de la rebel-lió de Tortosa, perquè, quan no hi haguera altres motius, bastarien els ferms vincles socials i econòmics existents amb les terres del Maestrat de Montesa, de Morella i la Plana de Castelló, on els veïns, el bisbe i el Capítol tortosins posseïen béns, rendes i fruits estimats en 50.000 rals de vuit.

D'altra banda, les circumstàncies eren molt diferents en relació amb les de 1640, quan les institucions valencianes aportaren els mitjans que tenien a l'abast per tal d'evitar la pèrdua de Tortosa i d'impedir que es propagara la rebel·lió a terres valencianes. Pel contrari, en 1705, Catalunya i el País Valencià compartien els objectius polítics, els projectes econòmics i les inquietuds socials. El fort descontentament cap a la dinastia francesa i a la seua acció de govern era també comú i transcendia l'àmbit institucional per projectar-se cap a totes les capes socials. La repressió aplicada per les tropes borbòniques en trànsit cap a Catalunya, amb l'incendi i la destrucció d'algunes poblacions de la Marina, o les extorsions i els abusos comesos per les que bloquejaven Dénia i Vinaròs contribuïren a decantar voluntats cap a la causa austriacista. Al mateix temps, el triomf de la rebel-lió a Catalunya i el control de la Mediterrània per part de l'armada aliada posaven més en evidència la indefensió dels valencians i accentuaven el malestar entre la classe política, que ja no dubtava a fer saber a Felip V que perillava la fidelitat del Regne per la manca de defensa: «nuestra lealtad se halla en el último trance y en la más crecida confusión [...] y si vuestra Magestad. no se sirve mirarnos con piedad y socorrernos promptament, como la necesidad lo pide, este Reyno no puede mantenerse ${ }^{16}$. En octubre, el mateix Govern borbònic donava per feta la pèrdua del Regne de València, fins al punt d'ordenar la sortida dels dos regiments que bloquejaven Dénia i Vinaròs, a fi d'evitar que caigueren en mans dels rebels, una decisió finalment revocada per la protesta enèrgica i general que va provocar. En definitiva, la més absoluta indefensió per terra i per mar i l'exhibició de força per part dels aliats, a més de les raons exposades anteriorment, feien inevitable el triomf austriacista al País Valencià. Per acabar-ho de rematar, el dia 30 de novembre, es van emetre dos Reials Decrets. El primer declarava rebels i enemics els catalans i ordenava la confiscació i el segrest de tots els seus béns, i el segon prohibia el comerç amb Catalunya. Aquestes disposicions constituïren un colp dur per als altres Regnes de la Corona d'Aragó, atès que mantenien vincles familiars, socials, econòmics, culturals i polítics molt estrets amb el Principat ${ }^{17}$.

Els plans dels aliats, tal com l'arxiduc havia expressat en el manifest publicat el mes d'agost, eren els de concentrar totes les forces en l'empresa de ser proclamat rei a Barcelona i deixar per a una segona fase les operacions conduents a obte-

15. AHN, Consejos, Estado, lligall 279, carta de l'arquebisbe a Grimaldo de 9 d'octubre de 1705.

16. Ibídem, representacions dels Estaments, la Diputació i la Ciutat de València al rei de 9 i 10 d'octubre de 1705 .

17. AHN, Consejos, 1lib. 2.451, f. 256v.-257v. 
nir l'obediència dels valencians. Va ser, però, un fet imprevist el que va capgirar aquestes previsions: el regiment de catalans que bloquejava Dénia a les ordres de don Rafael Nebot va decidir abraçar la causa austriacista. Aquesta circumstància va permetre que els assetjats abandonassen el marquesat i iniciassen la marxa cap a la capital del Regne, que capitulà davant els generals Basset i Nebot el dia 16 de desembre de 1705. D'aquesta manera, amb a penes alguns centenars de soldats catalans i el suport i l'entusiasme d'amplis sectors socials, els valencians proclamaren rei l'arxiduc sense que fos necessària la presència de tropes aliades.

A partir d'aquells moments, i units per uns mateixos interessos, es va estrènyer la vinculació entre Catalunya i València. A finals de gener de 1706, i gràcies a l'arribada d'importants contingents de tropes aliades i de miquelets catalans, la ciutat de València es va poder alliberar del bloqueig al qual va ser sotmesa per part de l'exèrcit borbònic i escapar així d'una ja prevista suspensió dels Furs (Pérez Aparicio, 2008: II, 358-360). Poc temps després, quan la ciutat de Barcelona va ser assetjada per les tropes de Felip V, els valencians contribuïren, especialment amb cavalls, a defensar-la, seguiren amb força preocupació l'evolució dels esdeveniments i celebraren amb tota mena de festejos la retirada de Felip V i les seves tropes de Catalunya ${ }^{18}$. Poc després, el triomf de les rebel-lions a la Corona d'Aragó es va completar amb les dels Regnes d'Aragó i Mallorca, però aquesta trajectòria compartida es va truncar un any després amb la victòria borbònica d'Almansa, el 25 d'abril de 1707, que permeté que Felip V iniciara immediatament la recuperació dels Regnes de València i Aragó.

\section{La victòria borbònica d'Almansa i la lluita per la supervivència}

Davant l'arribada de l'exèrcit vencedor, i d'acord amb les ordres procedents de Barcelona, el govern austriacista abandonà la ciutat de València camí del Principat. L'acompanyaren moltes famílies valencianes especialment vinculades a la causa de l'arxiduc, una xifra que alguns dietaristes eleven fins a 5.000 persones. A diferència de Barcelona, protegida per la fortalesa de Montjuic, la capital del Regne mancava absolutament de recursos defensius. Situada en una planura, tan sols estava cerclada per una muralla incapaç de suportar un atac amb tots els ets i uts, i més encara en aquelles circumstàncies, perquè tota l'artilleria havia estat traslladada al Principat o distribuïda entre les poblacions que estaven en condicions de resistir. El mateix virrei, comte de la Corzana, en abandonar la capital, havia recomanat al govern municipal que no oferís resistència al vencedor, a fi d'evitar les represàlies borbòniques i la destrucció de la ciutat ${ }^{19}$.

No obstant això, el triomf borbònic marcà l'inici de la resistència. De fet, la capital trigà dos dies a fer efectiva l'obediència als ducs d'Orleans i Berwick,

18. L'evolució dels esdeviments a Catalunya fou recollida pel dietaristes de l'época. I. PLANES, Sucessos fatales de esta Ciudad y Reyno de Valencia, volum I, Biblioteca Valenciana, ms. 159; Ortí I MAYor, Diario de lo sucedido en Valencia desde el día 3 de octubre de 1700, hasta el día $1^{\circ}$ de septiembre de 1715, Biblioteca Històrica de la Universitat de València (BHUV), ms. 460.

19. AMV, Lletres Reials, h3 16, f. 212. 
el 8 de maig de 1707, a causa d'una violenta reacció popular. El temor al càstig col-lectiu i a la repressió individual, que prendria forma en la supressió dels Furs i Privilegis del Regne, la imposició de fortes multes, empresonaments i confiscacions, estava més que justificat per les disposicions adoptades pel govern borbònic al llarg de 1706, a mesura que l'exèrcit va anar recuperant algunes poblacions. Així havia esdevingut a la ciutat d'Oriola, capital de la Governació dellà Xixona, que fou saquejada per resistir-se a prestar obediència a Felip V, va veure abolits els seus Privilegis, governada pel nou virrei, don Lluís Belluga, sense respectar els Furs, sotmesa al control de l'exèrcit i obligada a satisfer elevades quantitats de diners i grans per a mantenir les tropes ${ }^{20}$ (Castellví, 1997: II, 190-195).

Consumat el domini borbònic de la capital i amb aquests antecedents i d'altres, la preocupació principal de la classe política va ser la d'obtenir el perdó reial per a evitar el que semblava inevitable. Foren els tres Comuns valencians, Ciutat, Regne i Diputació, els que posaren en marxa tota una sèrie d'iniciatives per a obtenir el perdó del rei i tractar de pal-liar així el càstig per la rebel·lió. Cal dir, d'entrada, que aquesta iniciativa institucional, pacífica, va estar protagonitzada pels més fidels seguidors del Borbó, molts dels quals havien patit represàlies i confiscacions sota el govern de l'arxiduc, i es va traduir en una sèrie de missives al rei, a la reina, a destacats membres de la Cort i, fins i tot, al mateix rei de França, per tal que actuaren de mediadors davant Felip $\mathrm{V}^{21}$. El perdó reial va arribar amb un Decret de 5 de juny ${ }^{22}$, que, això no obstant, es limitava a la pena de la vida i altres penes corporals dels que abandonaren les armes, però no va evitar el Decret d'abolició dels Furs, signat el 29 de juny de 1707. Fou llavors quan la Ciutat de València acordà l'elaboració d'un memorial per manifestar com d'injust i d'injustificat era aplicar aquell càstig a tots els valencians de forma indiscriminada i en el qual posava de manifest la indefensió que havia patit el Regne. Aquesta vegada, fou el duc de Medinaceli i Cardona, també duc de Sogorb i marquès de Dénia, qui va fer a mans de Felip V la petició de recuperar els Furs, amb la contundent resposta per part del Borbó d'ordenar el trasllat al castell de Pamplona de don Josep Ortí i don Antoni Blanquer, artífexs de la iniciativa. Amb tot, aquesta reivindicació va ser molt present al llarg del regnat del primer Borbó - també dels seus successors-, període en el qual no mancaren els anuncis de devolució de tots els Furs que no foren contraris a la sobirania reial ni les reiterades peticions respecte a aquesta qüestió, sense que, finalment, els valencians veieren restaurat ni tan sols el dret civil, que sí que conservaren uns altres territoris de la Corona d'Aragó (Peset, 1972; Pérez Aparicio, 2009).

Aquesta ofensiva institucional fou paral-lela a un ampli moviment de resistència armada. Després d'Almansa, els aliats ordenaren la ràpida retirada de les restes del seu exèrcit cap a Catalunya, però deixaren guarnicions militars en les poblacions fortificades. Es tractava d'entrebancar l'avenç de l'exèrcit borbònic i de mantenir aquells enclavaments estratègics que, en un futur més o menys

20. Castellví, Narraciones históricas, op. cit., II, p. 190-195.

21. AMV, Lletres missives, g3 64, f. 1r.-12r.

22. BHUV, ms. $17 / 2$. 
immediat, pogueren afavorir una contraofensiva aliada. D'altra banda, molts austriacistes valencians es disposaren a resistir amb les armes a la mà. Les milícies valencianes contribuïren a defensar les places fortificades i molts voluntaris —els miquelets - combateren, en una guerra de guerrilles, contra les tropes ocupants. En tot moment, disposaren del suport aliat i dels miquelets catalans i, al mateix temps, participaren de forma molt activa en totes aquelles operacions que tenien com a objectiu rebaixar la pressió militar borbònica sobre Catalunya. Ho van fer establint una directa i estreta col-laboració entre l'austriacisme militant de totes dues bandes del riu de la Sènia.

Com és sabut, malgrat les conseqüències transcendentals i immediates que es derivaren de la batalla d'Almansa, especialment per als valencians i els aragonesos, aquesta batalla no significava el final de la guerra, ans al contrari. El primer obstacle amb què toparen els vencedors fou Xàtiva, que es va mostrar disposada a resistir fins a les últimes conseqüències, la qual cosa va obligar el cavaller d'Asfeld a prendre la ciutat a l'assalt, el 24 de maig, i a lluitar casa per casa, carrer per carrer, en una dramàtica i sagnant operació, que va culminar unes quantes setmanes després amb l'ordre de destruir-la, incendiar-la i deportar-ne els habitants a Castella (Castellví, 1997: II, 363-365)². A la mira d'aquests esdeveniments, Alzira va capitular, sense resistència, el 5 de juny i tot seguit les tropes borbòniques s'encaminaren cap a Dénia. A primeries de juliol començà l'atac, però el setge no va donar els resultats previstos (Castellví, 1997: II, 365-367) ${ }^{24}$.

Al mateix temps, l'exèrcit havia iniciat una sèrie d'operacions al nord del País amb els ulls posats en Tortosa. La importància d'aquesta empresa requeria, això no obstant, llargs preparatius abans de posar-hi el setge. Calia, doncs, actuar prèviament en les comarques valencianes veïnes, especialment als Ports i al Maestrat, en aquell moment un veritable escut protector de les terres de l'Ebre, i on encara existien distints focus de resistència, el més important dels quals era Morella. D'Asfeld començà per atacar Xert a primeries de setembre, però no era fàcil dominar aquelles terres, perquè les dificultats orogràfiques exigien un esforç considerable per recuperar unes poblacions fortament austriacistes, que, a més, disposaven del suport dels miquelets catalans i necessitaven després guarnicions que n'asseguraren l'obediència, uns recursos militars que eren molt necessaris a Catalunya ${ }^{25}$.

La recuperació de la ciutat de Lleida — que no del castell— per part dels borbònics, el dia 13 d'octubre, els permeté intensificar les operacions al nord del País Valencià. L'objectiu següent fou Ares, una població situada en la part més abrupta del Maestrat i dotada d'una fortalesa inexpugnable, malgrat que només disposava d'una petita guarnició. A les darreries de novembre, les tropes franceses de Felip V entraren a sang i foc en la població, però no aconseguiren ocu-

23. Castellví, Narraciones históricas, op. cit, II, p. 363-365. MiÑANA, De bello..., op. cit., p. 558-565, La Guerra..., op. cit., p. 203-212.

24. Castellví, Narraciones históricas, op. cit, II, p. 365-367. MiÑANA, De bello..., op. cit., p. 566-567, La Guerra..., op. cit., p. 212-214.

25. Planes, Sucessos fatales..., op. cit., volum i, f. 208v.-209r. i 246r.-v.; Miñana, De bello..., op. cit., p. 573-574; La Guerra..., op. cit., p. 224-225. 
par-ne el castell i s'hagueren de retirar ${ }^{26}$. Des d'allí, l'exèrcit es traslladà a Morella, que, a més de ser capital de la comarca dels Ports, gaudia d'un enclavament estratègic i d'una formidable fortalesa, des de la qual dominava una vasta extensió de territori a cavall entre els tres Regnes peninsulars de la Corona d'Aragó. En aquells moments, era també el refugi de molts austriacistes valencians, alguns dels quals havien ocupat càrrecs rellevants durant el govern de l'arxiduc. Els aliats havien dotat Morella d'una guarnició de tropes angleses i portugueses, a les quals calia afegir les milícies pròpies i un important contingent de miquelets valencians, catalans i d'altres procedències que hi tenien la base. El 4 de desembre, començà el setge formal i, tres dies més tard, es va iniciar el bombardeig que va acabar amb l'entrada de l'exèrcit el dia $12 \mathrm{i}$ amb la capitulació del castell el dia $17^{27}$. La pèrdua de Morella deixà Tortosa en el punt de mira i en l'objectiu immediat de les operacions militars borbòniques. També va constituir un dur colp per a l'austriacisme valencià: «será de grande consecuencia para poner freno a los migueletes, que tenían allí su retirada, para salir a robar en este Reyno», en paraules del dietarista borbònic Planes ${ }^{28}$.

Pas a pas, no sense dificultats, l'exèrcit borbònic anava consolidant el domini sobre el territori. L'any 1708, es va iniciar, amb un nou triomf, la rendició d'Alcoi el 9 de gener ${ }^{29}$ (Santonja, 2008: 75-77 i 79-80). Malgrat tot, Dénia es mantenia fidel a l'arxiduc $\mathrm{i}$ els miquelets continuaven molt actius a la Marina, on intentaren establir bases d'operacions noves a Guadalest i Finestrat. L'ajut prestat pels austriacistes catalans a través del port de Dénia era vital perquè poguessen sobreviure. No obstant això, la campanya militar de l'any 1708 tenia com a primer objectiu Tortosa. Els preparatius s'iniciaren a les darreries del mes de maig i principis de juny. Com en els esdeveniments de 1640, el setge de Tortosa esdevenia de vital importància per als valencians, si bé en 1708 les postures estaven dividides: d'una banda, els austriacistes, en connexió amb els catalans i l'exèrcit aliat, disposats a impedir que la ciutat caiguera en mans de l'exèrcit borbònic; de l'altra, els seguidors de Felip V, que donaven suport a les operacions militars del seu exèrcit.

Conscients de la transcendència de l'operació, el govern de Catalunya tractà de posar en marxa distintes iniciatives per tal d'evitar el setge. Entre aquestes iniciatives, Miñana, l'historiador valencià, destaca l'intent de provocar una nova rebel-lió al País Valencià que obligara els borbònics a retirar-se o, almenys, a dividir els seus efectius. L'operació resultà fallida. En comparació amb els fets de 1705, quan Dénia, primer, i la capital, després, proclamaren rei l'arxiduc sense comptar amb tropes aliades, les circumstàncies havien canviat radicalment. Hi havia un exèrcit d'ocupació al territori per a evitar noves rebel-lions, les pobla-

26. Ibídem, p. 576 i 228-229, respectivament.

27. Mĩ̃ana, De bello..., op. cit., p. 576-577; La Guerra..., op. cit., p. 229-231; Planes, Sucessos fatales..., op. cit., volum I, f. 233v., 234r. i 243v.-244v; CASTELlví, Narraciones históricas, op. cit., volum II, p. 368.

28. Planes, Sucessos fatales..., op. cit., volum I, f. 234r.

29. Miñana, De bello..., op. cit., p. 577-580; La Guerra..., op. cit., p. 231-235; Castellví, Narraciones históricas, op. cit., volum II, p. 546-547. 
cions estaven desarmades i els aliats havien de concentrar tots els seus efectius a Catalunya. Fracassat aquest intent, es va establir un pla per tal de reagrupar totes les quadrilles de miquelets — l'única força armada del austriacisme valencià en aquells moments - disperses per les muntanyes després de la caiguda de More1la. Es tractava d'aprofitar la reduïda presència d'efectius militars borbònics a les comarques del nord per a prendre una plaça forta que els servira de base d'operacions des d'on pogueren impedir el subministrament de provisions i pertrets a les tropes borbòniques que operaven en Catalunya.

La població elegida va ser Sogorb, situada en la comarca de l'Alt Palància, als peus d'un turó coronat per un alcàsser. El seu interès estratègic raïa en el fet d'estar situada en la principal via de comunicació amb el Regne d'Aragó i pròxima al camí entre València i Catalunya, molt transitat en aquells moments pels combois militars. Cap allí van confluir uns quants centenars de miquelets amb la intenció d'ocupar-la els primers dies de juny de 1708, mentre uns vaixells anglesos es deixaven veure des de la platja de València, per tal de fomentar una nova rebel-lió a la capital que no s'arribà a produir. Malgrat que l'operació semblava que disposava del suport dels segorbins, la ràpida resposta del governador de València, don Antoni del Valle, i l'arribada de reforços des de Terol aconseguiren vèncer la resistència dels miquelets i fer-los abandonar l'empresa ${ }^{30}$.

Aquest fracàs d'obrir un nou front austriacista al País Valencià convertí Tortosa en el nou escenari de confrontació. La ciutat de l'Ebre constituïa un enclavament estratègic de vital importància per a Catalunya i, per la proximitat amb el Regne de València, n'era considerada també l'antemural. Per aquestes raons, el govern de l'arxiduc havia dut a terme diverses obres de fortificació després de la batalla d'Almansa i hi va concentrar importants contingents militars. Al llarg del mes de juny, es feren els preparatius necessaris per a iniciar l'atac, que durà fins als primers dies de juliol. El dia 10, els assetjats demanaren la capitulació, que es va fer efectiva l'endemà davant el duc d'Orleans, qui també va exigir el lliurament de la fortalesa d'Ares del Maestrat, que estava sota el comandament del governador de Tortosa ${ }^{31}$. Amb aquesta pèrdua, l'austriacisme valencià va patir un dur colp: «se entregó Tortosa, con la cual se tenía más en freno a los rebeldes del reino de Valencia, que se habían unido a los catalanes ${ }^{32}$.

Assolit aquest important objectiu, les operacions militars al País Valencià evolucionaren de manera ràpida i favorable per a l'exèrcit borbònic, que pogué encarar amb més possibilitats d'èxit la recuperació dels ja únics bastions austriacistes: Dénia i Alacant. Prompte començaren els preparatius per a assetjar la capital del marquesat, que disposava d'una important guarnició angloportuguesa formada per 1.500 soldats, milícies valencianes i nombrosos miquelets, als quals

30. Miñana, De bello..., op. cit., p. 589-593; La Guerra..., op. cit., p. 247-252; OrTí I MaJOR, Diario..., op. cit., p. $280 \mathrm{v}$.

31. Una còpia de les capitulacions de Tortosa en CASTELlví, Narraciones históricas, op. cit., volum II, p. 575-578. El capítol referit a Ares és el número 22.

32. Bacallar i Sanna, Comentarios..., op. cit., p. 156-157; Castellví, Narraciones históricas, op. cit., volum II, p. 526-534 i 579; Miñana, De bello..., op. cit., p. 587-588 i 593; La Guerra... op. cit., p. 246 i 252. 
es van sumar distints reforços enviats des de Catalunya. Per contra, a les darreries d'octubre, arribaren des del Principat més de 10.000 efectius, 24 canons i 9 morters, «excesivo número para la débil plaza de Denia», segons l'opinió de Castell$v^{\prime 3}{ }^{33}$. La forta concentració de tropes i d'artilleria responia a la importància que tenia per als dos contendents, però també generava grans expectatives entre maulets i botiflers. Per als primers, Dénia era el bressol de l'austriacisme, refugi de miquelets i pont de comunicació marítima amb Catalunya i les Illes. Per als segons, prevalia el desig d'eradicar tots els reductes de dissidència, amb l'esperança de veure's lliures de la presència de l'exèrcit i de les fortes càrregues i abusos que patien i, al mateix temps, d'acabar amb el focus més important de l'activisme proaustríac, una ciutat «llena de todos los hombres facinerosos de este Reino, siendo el asilo de todos los pícaros, de donde salen por mar y tierra a insultar, robando a los pasajeros ${ }^{34}$. Els preparatius per a l'assalt començaren el 5 de novembre. El resultat fou l'entrada de les tropes el dia 12 i la capitulació del castell el 17.

Des de Dénia, les tropes prengueren el camí d'Alacant. La ciutat havia estat dotada pels aliats d'una nombrosa guarnició, a més de les milícies locals i un gran contingent d'uns 5.000 miquelets, d'acord amb la seua importància estratègica, derivada de ser el millor port marítim valencià i de posseir una fortalesa imponent. El primer pas era ocupar la ciutat i tractar d'impedir qualsevol comunicació entre el castell i el mar, l'única via per la qual podria rebre ajut. El 3 de desembre, el comandant de la guarnició oferí la rendició per tal d'evitar els estralls de l'assalt i, a canvi de conservar el castell a l'espera de reforços. No obstant això, l'arribada d'un estol aliat amb tropes de desembarcament, el 15 d'abril de 1709 , no va poder aconseguir els seus objectius i, finalment, el castell va capitular el dia $19^{35}$.

Dos anys, des del 25 d'abril de 1707, tardà l'exèrcit borbònic a vèncer la resistència militar i controlar el País Valencià. No obstant això, sense el paraigua protector de les places i les guarnicions aliades, la dissidència es mantingué molt activa, ja fóra amb les contínues operacions dels miquelets contra els combois militars borbònics i contra les poblacions i els botiflers més significats, ja fóra amb els contactes continus amb Catalunya, afavorits per la presència d'espies $i$ per una intensa correspondència amb el Principat, que trobava en el mar una via

33. Castellví, Narraciones históricas, op. cit., volum II, p. 547-548. Planes recollí també notícies abundants sobre els preparatius del setge a Dénia i l'evolució dels esdeveniments. Aquestes notícies formaven part del volum II del seu dietari — avui en parador desconegut - i foren publicades en el diari Las Provincias. L'esmentat volum va pertànyer a don Josep Martínez Aloy. Les notícies relatives a aquest volum han estat tretes de l'esmentat diari, la referència de les quals és donada per la data que hi figura. La Biblioteca Valenciana posseeix, en el Fondo Carreres, signatura 2.542, els retalls de premsa que recullen les notícies extretes del dietari.

34. Planes, Sucessos fatales..., op. cit., volum II, anotació corresponent al día 10 de novembre de 1708.

35. AHN, Estado, leg. 350-2, el contingut de les capitulacions de la Ciutat en carta del cavaller d'Asfeld a don Josep de Grimaldo datada en Alacant el 3 de desembre. Sobre tots aquests esdeveniments, vegeu CASTEllví, Narraciones históricas, op. cit., volum II, p. 618-621; MiÑanA, De bello..., op. cit., p. 598-600 i 603-604; La Guerra..., op. cit., p. 259-261 i 264-265. 
segura i ràpida de comunicació. Les raons d'aquesta activitat intensa eren provocades pel creixent descontentament cap al Govern borbònic a causa del progressiu i insuportable augment de la fiscalitat, el desprestigi dels nous ministres, acusats de lladronici, o la presència de l'exèrcit i els abusos practicats sobre una població vençuda, que no feien sinó mantenir viva l'esperança d'un retorn al domini austriacista amb la recuperació consegüent dels Furs. En aquest sentit, la difusió contínua de notícies, com la que circulà en juny de 1709, sobre l'arribada imminent de l'arxiduc per a recuperar el País amb l'ajut dels miquelets, o la presència en Tarragona d'un estol anglès amb la missió de traslladar tropes a les costes valencianes, o fins i tot la veu d'haver-se produït ja un desembarcament en Alacant, contribuïa a alimentar la dissidència i a crear un clima general d'inseguretat, amb el qual es pretenia que «estas voces causen recelos y temor para que Felipe V, nuestro Rey, mande retirar a este reino soldadesca de la que tiene en Cataluña, disminuyendo su ejército en Cataluña» ${ }^{36}$.

L'any 1710 va estar marcat per grans esdeveniments que van ser a punt de canviar el rumb de la guerra. A començament de l'estiu, poc abans que Felip V començara la campanya militar, es va posar en marxa una nova operació de diversió de l'exèrcit borbònic a Catalunya. Es tractava d'organitzar una nova sublevació al País Valencià amb el desembarcament de tropes angleses. Les notícies que comunicava el comandant borbònic a l'Ajuntament de València, el 4 de juliol, avisaven de la presència en Salou d'un estol aliat, de més de quaranta naus angleses, destinat — en opinió de Caetano — a algun port proper a la capital per a afavorir la sublevación ${ }^{37}$ La realitat, però, fou molt diferent. El desembarcament de miquelets — que no de tropes regulars - es va intentar fer a les platges de Vinaròs i Orpesa, potser amb la intenció d'assaltar i destruir el gran magatzem de gra que hi havia ${ }^{38}$.

Els esdeveniments militars de l'estiu, amb les victòries aliades d'Almenara i Saragossa, capgiraren de dalt a baix el rumb de la guerra. L'arxiduc entrà de nou a Saragossa, i Aragó recuperà els seus Furs, mentre es desfermava un clima d'intensa eufòria entre els austriacistes valencians, que consideraven imminent l'arribada de Carles III: «quanto antes será lo mismo en Valencia, pues están los ánimos deseosos de ver abrogadas las leyes castellanas, su papel sellado y los aloxamientos de los paysanos en esta Ciudad y Reyno extinguidos», quelcom que, per al dietarista borbònic Planes, representava «el mal de los males» ${ }^{39}$. No obstant això, els aliats decidiren donar prioritat a l'entrada en la capital de la Monarquia, perquè consideraren que bastaria enviar un petit cos d'exèrcit a València per a aconseguir recuperar-la, però l'operació va fracassar. La presència, a primeries de setembre, de vuit embarcacions enfront del Grao, amb el nou

36. Planes, Sucessos fatales..., op. cit., volum II, dies 4, 19 i 22 de juny i 12 i 17 d'agost de 1709.

37. AMV, Libros Capitulares, D 7, f. 142-143, deliberació d'1 de juliol de 1710. La carta de Caetano en D 8, f. 168.

38. Planes, Sucessos fatales..., op. cit., volum III, f. 69r., 76r., 77r. i 78v.

39. Ibídem, f. 98v.-99r., dia 30 d'agost de 1710. L'Ajuntament escrigué immediatament una carta al rei per a manifestar el seu pesar per la desteta i oferir-se per al que fos necessari. AMV, Lletres Missives, g 3 65, f. 32v.-33r. 
virrei austriacista, el català comte de Savallà, mil catalans de desembarcament i molts dels valencians que estaven a Barcelona no fou suficient davant les amenaces del governador, don Antoni del Valle, de bombardejar la ciutat si es produïa la rebel·lió ${ }^{40}$. També resultà fallida l'empresa d'ocupar el tron, i l'arxiduc hagué d'abandonar Madrid mentre les tropes aliades patien les severes desfetes de Brihuega i Villaviciosa, de 9 i 10 de desembre. El rumb de la guerra es decantava de nou a favor de Felip V.

L'any de 1710 es va tancar amb mals auguris per als aliats i, per tant, per als austriacistes valencians, que, no obstant això, mantingueren una intensa activitat $\mathrm{i}$ comunicació amb Catalunya, alimentada també per tants valencians com havien trobat refugi al Principat i desitjaven ansiosament restaurar el sistema foral. Un fluid intercanvi de correspondència i la contínua difusió de notícies sobre suposades arribades de l'armada anglesa i holandesa i de desembarcaments aliats continuaren al llarg de 1711 i 1712, i foren una arma molt eficaç per a mantenir activa la dissidència i en peu de guerra els miquelets. Fins i tot en 1713, evacuades ja les tropes de Catalunya i assetjada Barcelona per l'exèrcit de Felip V, a València, va córrer la veu — sorprenent — de l'arribada d'una gran armada procedent del nord d'Àfrica, disposada a assetjar la ciutat per tal d'alleujar la pressió militar sobre la capital del Principat ${ }^{41}$.

També des de Barcelona s'alimentava l'esperança que es produís un canvi de rumb amb la possibilitat de disposar d'una rebel-lió de valencians i aragonesos, oprimits per una dura repressió i disposats a contribuir a l'empresa comuna de la llibertat, si les circumstàncies eren favorables. Així s'expressava don Manuel Ferrer i Sitges en la transcendental reunió celebrada pel Braç Militar el 6 de juliol de 1713:

Los Regnes d'Aragó i València, que és just considerem com a nostres germans, units per tantes centúries en tants solemnes repetits actes de Corts generals en indissoluble separació, companys en tantes conquistes, que vui violentment sufren la més dura i tormentosa despotiquès i que en nostres dies han sabut son gran valor i coratge, tan notori al món com llastimós a la memòria, defensar los privilegis i llibertats en indefensos pobles, comarques i muntanyes, si la sort los presenta la més perillosa ocasió, reprendran les armes i fent últim extermini de ses vides sacudiran tan insuportable servitud i ajudaran a la comuna empresa de la llibertat ${ }^{42}$.

La solidaritat dels valencians — i també dels aragonesos — residents a Barcelona no es va fer esperar. El comte de Cirat, don Gaspar Bernat Calatayud Vilarig i Carròs, i don Josep Vicent Torres i Eiximeno, en nom del Regne de València, manifestaven la voluntat de seguir la resolució dels Comuns catalans de prendre

40. Planes, Sucessos fatales..., op. cit., volum III, f. 100v. i s., dia 1de setembre i s.

41. Ibídem., volum III, f. 21v., 22r., 50r., 76r., 85v., dies 28 i 31 de març, 28 de juny i 2 de setembre de 1712 i volum IV, f. 186r., dia 4 d'agost de 1713.

42. Discurs de Don Manuel Ferrer $i$ Sitges. Aquest document forma part de l'obra de CASTELLVÍ, Narraciones históricas, op. cit, III, p.798. Ha estat publicat per J. AlbaredA (1996), Escrits polítics del segle XVIII, tom I, Despertador de Catalunya i altres escrits, Capellades, Eumo Editorial, p. 97-119 (la citació en la pàgina 113). 
les armes per a defensar i continuar la guerra en nom de Carles III i a favor de les lleis i els privilegis, com si foren nadius del Principat:

Desean los valencianos manifestar su constancia, celo y fidelidad a su legítimo rey y señor y dar a V. E. F. un verdadero testimonio de su reconocimiento siguiendo la tan laudable resolución en que V. E. F. deliberó publicar la continuación de la guerra en nombre del rey nuestro señor y conservación de las leyes y privilegios [...] La nación valenciana ha resuelto asegurar a V. E. F. que ha deliberado sacrificarse por las mismas razones junto con V. E. F. y que están prontos en concurrir en quanto V. E. F. considere poder contribuir a este justo y honroso fin, considerándoles como nativos de este E. y F. Principado ${ }^{43}$.

Es tractava també d'una decisió amb la qual els valencians volien correspondre al fet que Catalunya havia estat el suport principal de Jaume I en la conquesta del Regne «en la feliz expulsión de los moros de su Patria». Fruit ara d'aquesta col·laboració, unides Catalunya i València «en el honor y interés común», es formaren dos regiments, el de la Mare de Déu dels Desemparats i el de Sant Vicent Ferrer. El primer, d'infanteria reglada, fou comandat per Torres i Eiximeno, com a coronel, per Tomàs Anglesola, Joan Antoni Corradó i Francesc Maians, successivament, com a tinents coronels, i per Vicent Esteve de Lago, com a sergent major; el segon, de fusellers, estigué a les ordres de Joan Vila i Ferrer, primer, i de Josep Ortí, després. El tinent coronel era Ramon Bordes (Albertí, 1977: 148149, 164, 252, 382). Hi hagué, però, més valencians que agafaren les armes. Castellví recull la presència d'una companyia solta a les ordres del també valencià Josep Marco, anomenat el Penjadet. N'hi va haver d'altres que formaren part de diferents unitats com a oficials, entre els quals hi havia Francesc Carròs de Vilaragut, el coronel Felip Armengol de Folc, el capità de granaders Mulet, el també capità Manel Muñoz i altres ${ }^{44}$.

Això no obstant, si algun valencià brillà amb llum pròpia en la defensa de Barcelona fou Joan Baptista Basset i Ramos (Cervera, 2006; Pérez Aparicio, 1981 i 2008), qui, en la seua condició de general de batalla, va assumir el comandament de l'artilleria ${ }^{45}$. El gran líder austriacista popular havia estat processat en 1706 per les irregularitats comeses durant el seu govern, al qual s'afegí, un any després, un procés militar per haver abandonat la defensa de Dénia quan era assetjada per les tropes borbòniques. Aquest darrer procés va concloure amb un Reial Decret de 5 de gener de 1708, pel qual era «suspendido de todos los puestos y honores militares por el tiempo que será de mi Real agrado». (Pérez Aparicio, 2009.2: 163-164) A partir d'aquesta data, no hi ha referències a la situació de Basset fins al 1711, quan tot sembla indicar que, a causa del seu retorn a Viena, l'arxiduc va alçar la suspensió. La importància de la seua actuació com a general

43. Representación que en 12 de julio dieron los valencianos a los tres comunes de Cataluña ofreciéndose a la defensa de Barcelona, en CAstellví, Narraciones históricas, op. cit., volum III, p. 815.

44. Ibídem, volum IV, p. 36, 353-354, 357.

45. Ibídem, volum III, p. 695, 704. 
de l'artilleria en la defensa de Barcelona és sobradament coneguda gràcies a les memòries de Castellví. Com altres valencians, fou apressat l'11 de setembre i traslladat al castell d'Ondarrabia i després al de Segòvia, d'on fou excarcerat en 1724 a causa del seu precari estat de salut (Muñoz González-Catà Tur, 2005: 28-33, 37, 242-243, 247, 252-253). Allí morí, pobre, el 15 de gener de 1728 i fou soterrat per caritat en l'església de Santa Eulàlia de Segòvia ${ }^{46}$.

Amb l'ocupació borbònica de Barcelona, Felip V recuperava tot Catalunya i restava a l'espera de restablir la seua autoritat a les Illes. Només Menorca i Gibraltar quedarien, finalment, en mans angleses, però uns altres territoris importants, els Països Baixos, Milà, Nàpols o Sicília, foren desmembrats de la Monarquia Hispànica, amb la qual cosa es frustrà la creença de Carles II que només la Casa de Borbó podia garantir el manteniment de la seva integritat territorial. D’altra banda, els tractats d'Utrecht i de Rastatt acabaren també amb l'intent dels austriacistes de la Corona d'Aragó d'obtenir el reconeixement de la identitat politicoconstitucional de cadascun dels Regnes que la integraven. Fins i tot els borbònics valencians seguiren amb molta atenció les notícies segons les quals, en 1713 , l'emperador va proposar que els tractats recolliren la segregació dels territoris hispànics de la Corona d'Aragó:

Fue el emperador precisado a proponer la separación de la Monarquía de España. Y, en caso de no tener grata aceptación, ofrecer contentarse con la Corona de Aragón y quando ni de esta la tuviessse, con su fidelíssimo Principado de Cataluña y a todo trance con que quedasse libre y República bajo la Augustíssima Casa y de los aliados ${ }^{47}$.

Malgrat tot, l'esperança de recuperar els Furs es mantingué viva i aflorà en forma de peticions, ja fóra per part de les institucions valencianes, ja fóra de caràcter general per les capitals dels antics Regnes de la Corona, quan les circumstàncies eren especialment favorables a una receptivitat més gran per part dels monarques de la Casa de Borbó, sense que, finalment, aquestes aspiracions fores satisfetes.

\section{Bibliografia}

Albareda i Salvadó, J. (1993). Els catalans i Felip V: De la conspiració a la revolta (1700-1705). Barcelona: Ediciones Vicens Vives.

Albertí, S. (1977). L'onze de setembre. Barcelona, Albertí Editor, 3a ed.

Cervera Torrejón, J. L. (2006). Joan Baptista Basset: Vida i mort del líder maulet. València: Tres i Quatre.

Espino López, A. (2007). Guerra, Fisco y Fueros: La defensa de la Corona de Aragón en tiempos de Carlos II, 1665-1700. València: Universitat de València.

García Martínez, S. (1991). Valencia bajo Carlos II: Bandolerismo, reivindicaciones agrarias y servicios a la Monarquía. València: Ajuntament de Villena.

46. Agraïsc a don Alfonso Ceballos Escalera que m'haja facilitat la notícia i les dades de la seua mort.

47. Planes, Sucessos fatales..., op. cit., volum Iv, 218v. 
Molas Ribalta, P. (2000). «La razón de Estado y la sucesión española». A: La razón de Estado en la España Moderna. València, Publicacions de la Real Sociedad Económica de Amigos del País, 27-36.

Muñoz González, A. i CATÀ I Tur, J. (2005). Repressió borbònica i resistència catalana (1714-1736). Madrid: Muñoz-Catà.

PÉrez ApARICIO, C. (1981). De l'alçament maulet al triomf botifler. València: Tres i Quatre.

—(2008). Canvi dinàstic i Guerra de Successió: La fi del Regne de València. València: Tres i Quatre.

- (2009-1). «La respuesta de los valencianos a la abolición de los Fueros». A: La sociedad valenciana tras la abolición de los Fueros. València: Institució Alfons el Magnànim, 161-192.

3/4 (2009-2). "Don Juan Bautista Basset y Ramos. Luces y sombras del líder austracista valenciano". Estudis, Revista de Historia Moderna, 35, 133-164.

Peset Reig, M. (1972). «Notas sobre la abolición de los Fueros de Valencia». Anuario de Historia del Derecho Español, XLII, 657- 715.

Santonja, J. L. (2008). La desfeta d'Alcoi. Alcoi: SCA Ediciones.

Simon TARrés, A. (2011). Del 1640 al 1705. L'autogovern de Catalunya i la classe dirigent catalana en el joc de la política internacional europea. València: Universitat de València / Institut d'Estudis Catalans.

Torras i Ribé, J. M. (1999). La Guerra de Successió i els Setges de Barcelona (16971714). Barcelona: Rafael Dalmau Editor. 